\title{
A (DES)CONSTITUIÇÃO DO FEMININO EM O REMORSO DE BALTAZAR SERAPIÃO, DE VALTER HUGO MÃE
}

\author{
Ana Lúcia Montano Boessio
}

\begin{abstract}
RESUMO:
Este trabalho visa analisar o papel do contexto cultural na (des)constituição do feminino, através da relação entre a personagem principal e sua esposa em o remorso de baltazar serapião. Essa (des)constituição permite uma aproximação com o conceito proposto por Roy Wagner de cultura como invenção, o que, no mundo ficcional de mãe, torna-se uma chave de leitura sobre o feminino enquanto construção cultural.
\end{abstract}

PALAVRAS-CHAVE: Cultura; literatura de língua portuguesa; feminino.

\section{Introdução}

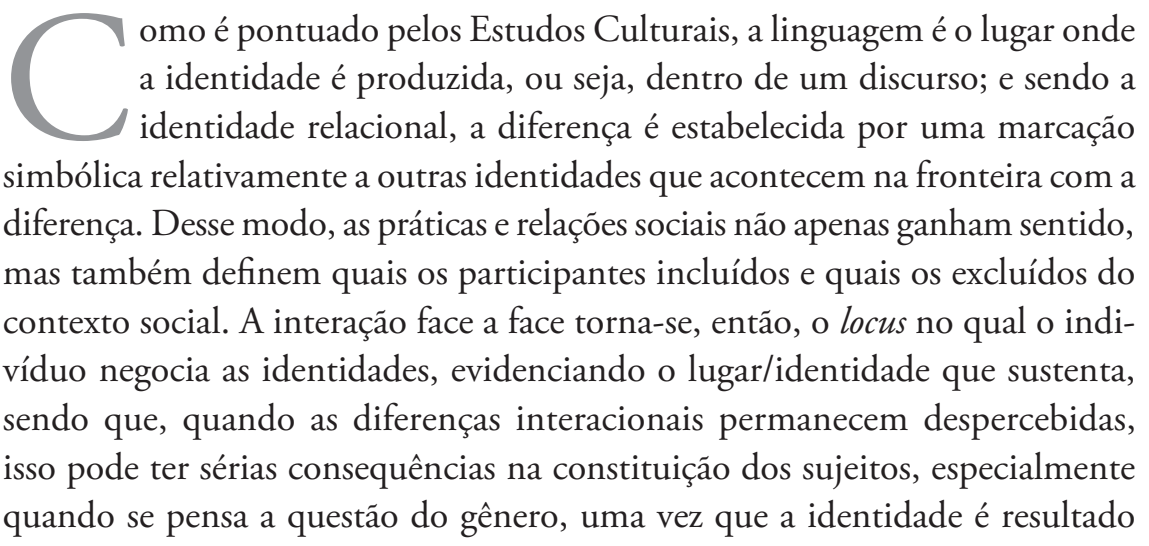


dos processos de identificação com determinadas comunidades de fala. Vale lembrar também que, de acordo com Bourdieu (1977), toda relação social é marcada pelo poder, e o valor do discurso depende das relaçóes de força entre um produtor e um consumidor desse discurso, o que significa que esse poder é permeado pela linguagem. Portanto, levar em conta o modo como as pessoas negociam identidades sociais, ou como a situação multilíngue se configura na comunidade, adquire grande relevância por tornar-se um elemento desvelador de uma cultura que se afirma e consolida tanto pelo não dito, pela ausência de voz de alguns membros da comunidade, quanto pelo que se apresenta de forma explícita. Sendo assim, o objetivo deste trabalho é analisar o papel do ambiente cultural na (des)constituição do feminino, através da relação entre "baltazar", personagem principal na obra de valter hugo mãe, o remorso de baltazar serapião, e sua esposa "ermesinda". Ressalta-se que o uso de letras minúsculas para nomes próprios e nos inícios de frase, a começar pelo seu próprio nome e pelo título da obra, é uma escolha do autor; segundo declaraçóes suas ao jornal O Globo, em 2011, uma estratégia de aproximação do texto escrito ao fluxo da linguagem oral. Talvez, também por compreender a relatividade desses construtos linguístico-culturais, uma vez que sofrem alteraçóes à medida que as posiçóes de poder se alteram na arena social.

\section{A genealogia social do universo de mãe: a cultura como "contrapeso"}

Entendendo cultura como uma construção antropológica e, segundo Roy Wagner (2012), uma "invenção", percebe-se o quanto um espaço marcado pelo isolamento e, consequentemente, por práticas culturais rígidas e inquestionáveis, pode influenciar no comportamento de um grupo, definindo suas dinâmicas na arena social. Na narrativa de mãe, o processo inter-relacional de constituição do sujeito, como proposto por Mikhail Bakhtin (1997), o qual requer a presença do "outro" para que o sujeito constitua a si mesmo, é completamente distorcido: o "outro" humano é transformado num objeto irreconhecível, ao mesmo tempo em que o animal recebe status de ser humano. Neste caso, a maior consequência é a desconstituição do sujeito feminino, que não apenas é privado de direitos sociais, mas também de voz, mobilidade, e até integridade física. Essa desconstituição, na obra de mãe, reflete o que Wagner chama de um aspecto coletivo de simbolização, dialeticamente identificado 
com um modo de cultura ético, ou moral. Como acontece ao antropologista, no mundo ficcional de mãe, Cultura é apresentada como um tipo de ilusão para ajudar o narrador/leitor a organizar suas experiências e entendimentos sobre o feminino como uma construção cultural e, portanto, limitada pelo tempo e pelo espaço.

"a voz das mulheres estava sob a terra, vinha de caldeiras fundas onde só diabo e gente a arder tinham destino" (MÂE, 2011, p. 11): assim inicia o romance de valter hugo mãe, situando o locus de enunciação das mulheres como uma voz infernal, "perigosa e burra", que estava "abaixo de mugido e atitude" da sarga, a vaca da família; uma narrativa que desde a primeira linha (des) constitui a condição do feminino numa sociedade sem tempo e sem lugar, mas marcada por aspectos culturais essencialmente feudais. Num jogo dialético entre ser e não-ser, a obra de mãe caracteriza-se por um universo de vozes masculinas, assombradas, atormentadas por uma condiçâo social desprovida do direito de carregar um nome de gente - eles são os sargas e, na fala do próprio baltazar, "reunidos em família como pecadores de uma mesma praga" e fadados a se destituírem "lentamente de toda a pouca normalidade" (MÃE, 2010, p. 11). Uma relação distorcida com o outro, que não os reconhece na sua condição humana, nem mesmo de nascimento humano: diante da pequena comunidade a que supostamente pertence, a família de baltazar é percebida como "bichos desumanos", aparentados da sua vaca. E como se não bastasse, seu pai "pagava ainda a ousadia de se chamar afonso" (MÂE, 2010, p. 13), um nome de rei e em semelhança ao senhor da casa a que serviam. Como ouviam frequentemente,

uma ousadia disparatada, um sarga chamado afonso, um verdadeiro familiar da vaca como se viesse de um rei. quem não tinha do que se honrar, que diabo honraria aludindo a tal nome, perguntavam as pessoas ocupadas com nossa vida (MÃE, 2011, p. 13).

E assim seguiam os "sargas", carregando o contrapeso dos estigmas sociais, da tradição constituída, "andando de quatro e batendo seus cascos", tentando existir naquele pequeno mundo, fazendo de conta que não ouviam, que não entendiam; fazendo de conta que pertenciam. 
Como afirma Bourdieu (1977, p. 2), o universo social é um sistema de trocas simbólicas; e a ação social, um ato de comunicação, sendo que um dos deslocamentos a que a crítica sociológica submete os conceitos linguísticos é o de relaçôes de comunicação (ou de interação simbólica), que se configuram como relações de força simbólica, as quais vão alçar o discurso não apenas a uma questão de sentido, mas também à questão do valor e do poder do discurso, o que inevitavelmente desvela a posição do locutor na estrutura social. Vale, então, perguntar: que posição é essa de um sujeito impedido até mesmo de ser reconhecido pelo próprio nome - nome de gente? Como se configura o sistema de trocas simbólicas nesse universo onde os atos de comunicação se dão a partir de loci de enunciação tão discrepantes? Poder-se-á dizer que um animal, seja cachorro, gato ou vaca, ocupa espaço enquanto sujeito social, uma vez que se entende que o que configura um sujeito é justamente possuir e produzir linguagem? O que esperar de um indivíduo totalmente desprovido de valor e poder em relação aos seus iguais, já que não tem a priori sua condição humana reconhecida pelo grupo?

Ao que parece, pode-se esperar não apenas um discurso, mas uma prática tão destituída de reconhecimento da condição humana quanto esse suposto sujeito social o é - um sujeito deslocado, que buscará numa outra arena (a família) um interlocutor tão frágil e desprovido de força quanto ele próprio se sente diante da comunidade na qual está supostamente inserido; no caso, o sujeito feminino. E para resgatar a sua condição de interlocutor cujo discurso seja dotado de valor e poder, esse indivíduo precisará recorrer inevitavelmente às vozes que o constituíram, ou seja, ao contrapeso da sua tradição, às práticas e discursos daqueles que o antecederam. É esse deslocamento de uma condição humana para animal que se identifica na obra de mãe, na voz de baltazar, e que desde as primeiras páginas torna evidente a posição do locutor (masculino) no contexto, assim como a genealogia social do feminino enquanto sujeito desapoderado naquele universo.

Seguindo esse viés, Roy Wagner, em $A$ invenção da cultura (2012, Introdução), analisando a cultura, faz uma comparação entre certas ciências cujos paradigmas mantém uma imobilidade congelada, e a antropologia que, segundo o autor, é pura dialética, "um jogo de exposições (e refutaçóes) por vozes disparatadas ou uma eclética soma de tudo e mais um pouco dentro dos manuais". Ou seja, a antropologia é uma disciplina na qual "um autor é obrigado 
a destilar a sua própria tradição e seu próprio consenso" (WAGNER, 2012, p. 18), elegendo observar fenômenos humanos a partir de um "exterior" - entendendo que uma perspectiva exterior é tão profundamente criada quanto as nossas mais confiáveis perspectivas “interiores”. Desse modo, a própria cultura é apresentada como uma espécie de ilusão, um contrapeso (e uma espécie de falso objetivo) para ajudar o antropólogo a ordenar suas experiências. E é neste ponto que se pode estabelecer uma relação direta entre o fazer do antropólogo e o fazer do escritor literário ou, no caso, do narrador da obra de mãe, baltazar, que constantemente recorre aos referenciais culturais herdados da figura paterna para orientar-se e justificar suas atitudes na relação com o outro, em especial o outro feminino, sobretudo sua mulher, ermesinda, cuja presença silente ocupa completamente o mundo psíquico de baltazar. Nessa inter-relação, fica evidente o que Wagner chama de "dinâmica cultural" (2012, p. 26), a qual é baseada na mediação de domínios de responsabilidade (e não responsabilidade) humana. baltazar configura-se como um sujeito atormentado, justamente por entender-se como responsável por honrar o contrapeso da tradição de domínio masculino sobre a educação/controle do feminino, inclusive no que se refere ao papel da mãe em relação aos filhos, que deveriam ser protegidos ao máximo da sua influência, conforme narra a personagem:

a minha mãe deixava de falar comigo e com o aldegundes, porque lhe saíam coisas de mulher boca fora, e barafustar, como fazia, era encher os ouvidos dos homens com ignorâncias perigosas. uma mulher é ser de pouca fala, como se quer, parideira e calada, explicava o meu pai, ajeitada nos atributos, procriadora, cuidadosa com as crianças e calada para não estragar os filhos com os seus erros. ... liberta das intençóes de nos educar coisas inúteis ou falsas, que fizessem de nós rapazes menos homens ou simplesmente iludidos com um mundo que só as mulheres imaginavam (MÂE, 2011, p. 17).

Como representação do feminino, ermesinda, que se apresentava aos olhos de baltazar como "o anjo mais belo" que já vira, por sorte tão incrível, sua esposa, amor seu (MÃE, 2010, p. 65), apesar de desprovida de voz enquanto sujeito no "interior" daquele modelo social, constitui-se para o nar- 
rador num elemento perturbador, uma voz constante em sua mente, numa espécie de efeito contrastante, dialético. Esse contraste gera em baltazar uma crescente inquietação por ver-se induzido a reproduzir as práticas socioculturais do pai, desconstitutivas de um feminino com o qual estava "casado de igreja” e, portanto, autorizado para tê-la só sua e educá-la à maneira das suas fantasias, "como devia ser, como devia ser um pai de família, servido de esposa, a precaver tudo, a ter as vezes de responsável” (MÁE, 2010, p.22). À medida que o processo de desconfiguração física de ermesinda avança, começa a aflorar um princípio intuitivo, um desejo, se assim podemos chamar, de que talvez tudo pudesse ter sido diferente, o que culminará na verbalização do seu remorso nas duas últimas páginas do romance:

eu sentiria até ali o remorso dos bons homens, como havia pensado, remorso duro de tão dignamente administrar a educação da minha ermesinda. mas até ali, pensei, até ali, porque naquele momento, mais do que a condenação de restarmos os quatro encurralados para todos os avios, ocorreu-me a falha grave do meu espírito. e táo amargamente me foi claro que, por piedade ou compreensão com os meus companheiros, e talvez por ausência da voz da minha mulher, passara para lá do limite. o remorso dos bons homens já não me assistia, senão só a burrice e ignorância de quem abdicara da sua mulher (MÂE, 2011, p. 193).

Segundo Wagner (2012, p. 24), no aspecto coletivo da simbolização, os símbolos diferenciantes assimilam ou englobam as coisas que simbolizam. Este efeito, que "sempre opera para negar a distinção entre os modos", é o que o autor chama de "obviaçáa". Focalizando a atenção nesse "controle", o simbolizador percebe o modo oposto como algo bastante diferente, uma "compulsão" ou "motivação" interna. É o que parece acontecer com baltazar, assim como com todos os outros homens de sua família que o antecederam, representados pela figura paterna, os quais demonstraram ter a mesma compulsão por controle e desconstituição do "diferente"; neste caso, o feminino, aproximado na narrativa, como dito anteriormente, a uma figura endemoniada e, portanto, perigosa, sobretudo para o futuro do sujeito masculino. Como 
o narrador costumava dizer, "o mundo que as mulheres imaginavam era torpe e falacioso, viam coisas e convenciam-se de estupidez por opção...” (MÁE, 2011, p. 17).

\section{A perigosa presença do feminino}

Pensar o feminino pressupóe indubitavelmente tangenciar de alguma forma os estudos psicanalíticos e especialmente os trabalhos de Freud sobre a sexualidade e, mais especificamente, sobre a mulher. Entretanto, pensar o feminino implica voltar muitos séculos na história do ocidente; na verdade, milênios, se pensarmos na primeira referência à mulher enquanto representação de perigo para os homens: a imagem bíblica de Eva, responsável pela perda do paraíso sofrida por Adão. Desde então, as referências são muitas, tanto históricas quanto literárias. Podemos citar a perseguição às "bruxas", que teve início na Idade Média europeia e durou quase quatro séculos, resultando na morte de milhares de mulheres. Essa perseguição se acirrou depois da enorme devastação decorrente da peste negra, a qual vitimou $1 / 3$ da população europeia entre 1347 e 1350, aumentando os rumores de uma conspiração maligna que estaria tentando destruir os reinos cristãos. As bruxas, ou melhor, as mulheres, obviamente foram consideradas as propagadoras da praga. Inicia-se, então, uma caça desenfreada a mulheres consideradas hereges, praticantes de ritos pagãos e que, consequentemente, colocavam a instituição Igreja Católica em risco, sendo que o mais famoso manual de Caça às Bruxas surge em 1484, o famoso Martelo das Feiticeiras (Malleus Maleficarum).

O fato é que os séculos passaram, a Igreja enfrentou cisóes, mudanças diversas; novas vozes políticas, religiosas, filosóficas surgiram e ganharam força no mundo ocidental, as trocas simbólicas de que fala Wagner tornaram-se mais complexas, mas a ideia da mulher como figura infernal, "bruxa" perigosa (e, portanto, poderosa) parece continuar permeando e aprisionando a condição do feminino na sociedade. E apesar de muitas das práticas punitivas terem mudado, os tribunais da Inquisição, as fogueiras e enforcamentos terem sido banidos, ainda hoje presenciamos processos semelhantes de anulação física e moral, senão de esquartejamento: mulheres sendo privadas de voz na política, nas relaçóes profissionais, na família, na sociedade como um todo. Ao que parece, ainda forçadas a carregar o contrapeso de séculos de história desconsti- 
tutiva do seu valor, do seu locus de poder. E como o instrumento da literatura é a linguagem, essa invenção cultural do feminino encontra ali um espaço especial de desvelamento, um campo fértil para provocar, perturbar um sujeito social acostumado, como baltazar, a simplesmente reproduzir automatamente a sua tradição, fazendo com que no jogo linguístico entre signo, significado e significante, este último se distancie tanto do significado que quase se torne esquecido; um jogo que, levado às últimas consequências, como é o caso da escrita de valter hugo mãe, acaba gerando um estranhamento entre os muitos níveis de interlocução com e na obra, que potencializa sua força. Porém, como afirma Lacan (1955-56), a palavra é um "signo terrível", "quanto mais o significante nada significa, mais indestrutível ele é". É no trabalho sobre a linguagem que a obra de valter hugo mãe excede em força, em contraste, desvelando os deslocamentos nos processos de troca social e nos atos de comunicaçáo; é na escolha dos signos linguísticos, que retumbam ausência de voz, de poder na relação com o outro; que se delineia a sexualidade feminina; que a violência contra o feminino torna-se escândalo aos olhos do leitor.

Como é sabido, para Freud (1932), a feminilidade é uma conquista a ser alcançada pela menina; ou seja, ela não nasce mulher, torna-se mulher, sendo que, à medida que avança nas suas pesquisas, passando pelo complexo de Édipo e pelo complexo de castração, em A organização genital infantil, o autor vai chegar à conclusão de que a questão não é a primazia dos órgãos genitais (no caso, o pênis), mas sim "uma primazia do falo" (FREUD, 1923/1976, p. 180 ), o que resulta em um "sentimento de inferioridade" da menina em relação ao masculino. Segundo Soler (2006, p. 26), para Freud "a feminilidade da mulher deriva da sua condição de 'ser castrada'": mulher é aquela cuja falta fálica a incita a se voltar para o amor de um homem, esperando o falo daquele que o tem.

Essa questão do falo, da incompletude e inferioridade da mulher está presente em todas as personagens femininas de o remorso de baltazar serapião. Não apenas ermesinda, mas também a mãe e a irmã de baltazar, brunilde, a qual passou muito tempo sendo ensinada pela mãe sobre "as coisas que competiam às mulheres, [...], coisas da vida delas, daquele corpo belo mas condenado que carregavam, [...] aflitas com ciclos de maleitas que lhes eram naturais, [...], para se castigarem de inferioridade" (MÃE, 2011, p. 19). E, no que tange explicitamente a sexualidade feminina, temos a figura de teresa dia- 
ba - mulher de necessidades incontroláveis e jamais satisfeitas, e que passava os dias na praça do vilarejo à espera de alguém, qualquer um e/ou muitos ao mesmo tempo, que acalmasse o seu fogo:

parecia uma cadela no cio, farejando, aninhada pelos cantos das árvores e dos muros, à espera de ser surpreendida por macho que a tivesse. era toda carne viva, como ferida onde se tocasse e fizesse gemer. abria-se como lençóis estendidos e recebia um homem com valentia sem queixa nem esmorecimento. era como gostava, total de fúria e vontade, sem parar, a ganir de prazer. não queria mais nada senão esses ocasionais momentos, estropiada da cabeça, torta dos braços, feia, ela só servia de mamas, pernas e buracos, calada e convicta, era como um animal que fizesse lembrar uma mulher, [...]. eu sabia que mais de dez se punham nela. só ali éramos cinco, que o meu pai devia tê-la muito durante o dia,... (MÁE, 2011, p. 27).

Na obra de mãe, se a mulher tem voz ou movimento é assim, descontrolado, endiabrado, animalizado; elas não são chamadas pelo nome da vaca porque sequer ocupam o lugar de poder daquele animal, sequer são reconhecidas como parideiras daqueles sujeitos que detém voz numa estrutura social igualmente deslocada no tempo e no espaço. As mulheres de mãe destilam uma cultura inventada pelo homem, carregam o contrapeso de uma tradição que, se e quando questionada, nunca o é o suficiente para mudar a dinâmica de poder e voz na arena social. No universo fantástico de mãe, a tradição reevocada nas inter-relaçôes entre masculino e feminino não choca, não surpreende, não espanta nem mesmo o próprio feminino, enquanto personagem. Caberá ao leitor, quietamente, digerir cada palavra, cada nome minúsculo, cada vírgula na solidão e impotência da sua condição de "outro" na obra.

\section{Considerações finais}

Num misto de realidade e ficção, num jogo perfeito entre ética e estética, entre forma e conteúdo, a obra de mãe induz o leitor ao que Eagleton (2006, p. 6) chama de "consciência dramática da linguagem", a qual tem o poder de 
renovar nossas reaçóes habituais e nos fazer perceber "objetos" que nunca ou há muito tempo não eram percebidos. Porque o texto literário tem que "lutar com a linguagem de forma mais trabalhosa, mais autoconsciente do que o usual, o mundo que essa linguagem encerra é renovado de forma intensa”. E "intenso" por certo é um adjetivo que se aplica perfeitamente ao texto de mãe, que não poupa adjetivações e neologismos para provocar um leitor que constantemente (e talvez possamos dizer, inutilmente) busca no seu próprio contrapeso cultural discursos que contradigam aquelas práticas sociais, que as mantenham distantes de uma condição real, de qualquer dimensão do contemporâneo e, principalmente, de uma condição de atualidade, de modo a se acalmar, a fazer paz com o mundo ao qual pertence. E aqui o leitor/narrador aproxima-se do antropólogo, na tentativa de construir uma ilusão; como diria Wagner, de inventar, uma visão de mundo que dê conta de qualquer "irregularidade" como acidente. Mas o mundo de baltazar aproxima-se mais do que Sperber chama de "buraco negro", uma nuvem de poeira obscurante que

equivale ao lugar onde a referência cessa; obtém "conhecimento" ao se formar uma metáfora, mas trata-se de um conhecimento forjado em um âmbito pessoal por imitação de um conhecimento "enciclopédico" (isto é, convencional) mais amplamente sustentado (SPERBER apud WAGNER, 2012, p. 28).

O problema é que, na obra de mãe, as metáforas, e sobretudo o jogo entre elas, são difíceis, indigestas porque saturadas de questóes éticas das quais o leitor desavisado tenta escapar pelo fantástico da obra, mas a sua contraface, o real, calmamente o espera a cada início de sentença, em minúscula, com seus nomes em minúscula, o que por si só já se configura como uma provocação, um desafio e um aviso de que não será fácil fugir daquela trama de conceitos, imagens, sons e ritmos a exigirem desse leitor, também atormentado, o compromisso de sair de um estado de passividade e ver, ouvir e reconhecer: sim, o mundo de baltazar é um mundo não coincidente, "inatual", como diria Agamben (2009) e, portanto, podemos dizer, verdadeiramente contemporâneo. E, se contemporâneo, atual na sua inatualidade, consequentemente, é uma dimensão do real com o qual somos forçados a lidar porque impedidos de continuar negando. 
A discronia presente em o remorso de baltazar serapiáo, na voz do protagonista, torna evidente a sua consciência de que não pode fugir de si mesmo, o seu tempo, ou (des)tempo pertence a ele irrevogavelmente e isso é o seu conforto e a sua sina: eles são os "sargas" e assim permanecerão naquele mundo e naquele tempo. Mas aqui o leitor não encontra mais resguardo na figura do narrador, ele é deixado a esmo, entregue a si mesmo, ciente de que Cultura, e por consequência tradição, é matéria efêmera, intangível. Como o narrador, o leitor fica entregue a sua condição de contemporâneo e, como tal, na visão de Agamben, deverá manter o olhar fixo no seu tempo, não para perceber as suas luzes, mas o seu escuro:

... esse escuro não é uma forma de inércia ou passividade, mas implica uma atividade e uma habilidade particular que, no nosso caso, equivalem a neutralizar as luzes que provem $\mathrm{da}$ época para descobrir as suas trevas, o seu escuro especial, que não é, no entanto, separável daquelas luzes.

Pode dizer-se contemporâneo apenas quem não se deixa cegar pelas luzes do século e consegue entrever nessas a parte da sombra, a sua íntima obscuridade (AGAMBEN, 2009, p. 63).

Eis aí o poder do texto literário; eis aí a grande provocação da obra de mãe: que não neguemos as sombras do nosso tempo, as trevas multisseculares que uma cultura de culpa e segregação tem gerado, e que recorrentemente tem tido sua atenção e sua força voltadas para a (des)constituição de um feminino que, como ermesinda, insiste, persiste em existir, a despeito de toda violência sofrida. Resta saber se essa mulher conseguirá reconstituir e manter seu lugar de poder e voz num tempo e espaço suficientemente longos, a ponto de enterrar em definitivo uma tradição/invenção que insiste em se manter contemporânea e atual.

\section{Referências}

AGAMBEN, Giorgio. O que é o contemporâneo? e outros ensaios. Chapecó: ARGOS, 2009.

BAKHTIN, Mikhail. Estética da criação verbal. São Paulo: Martins Fontes, 1997. 
BOURDIEU, P. L'économie des échanges linguistiques. Langue Française, 34, maio 1977.

EAGLETON, Terry. Teoria da literatura. Uma introdução. São Paulo: Martins Fontes, 2006.

FREUD, Sigmund. (1932/1976). A Feminilidade. Em: Obras Completas. Vol. XXII. Rio de Janeiro: Imago.

. (1923/1976). Organização genital infantil: uma interpolação na teoria da sexualidade. In: Obras Completas. Vol. XIX. Rio de Janeiro: Imago.

LACAN, J. O Seminário livro 3, As psicoses. Rio de Janeiro, 1955-56.

MÃE, Valter Hugo. O remorso de baltazar serapião. São Paulo: Ed. 34, 2011.

MATTELARD, Armand; NEVEU, Érik. Introdução aos estudos culturais. São Paulo: Parábola, 2004.

MURRAY, Margaret. O Culto das Bruxas na Europa Ocidental. São Paulo: Madras, 2003.

Omartelodasfeiticeiras.http://pt.wikipedia.org/wiki/Ca\%C3\%A7a_\%C3\%A0s_ bruxas 14/05/2014.

RIBEIRO, Rosângela Maria. Relacionamento amoroso: sofrimento feminino na contemporaneidade. Dissertação de mestrado.Universidade Católica de Goiás, 2007. http://tede.biblioteca.ucg.br/tde_busca/arquivo. php?codArquivo=324. 28/04/2014.

SOLLER, C. (1997). O sujeito e o Outro I- Em: R. Feldstein, B. Fink, M. Jaanus (Orgs.); D. D. Estrada (Trads). Para ler o Seminário 11 de Lacan: Os quatro conceitos fundamentais da psicanálise. Rio de Janeiro: Jorge Zahar.

WAGNER, Roy. A invenção da cultura. São Paulo: Cosac Naify, 2012. 


\title{
THE (DE)CONSTITUTION OF THE FEMININE IN $O$ REMORSO DE BALTAZAR SERAPIÃO, BY VALTER HUGO MÃE
}

\begin{abstract}
:
The aim of this paper is to analyze the role of the cultural context in the (de)constitution of the feminine through the relationship between "baltazar", the main character in valter hugo mãe's work, o remorso de baltazar serapião, and his wife "ermesinda". Within this perspective, it is possible to relate that (de)constitution with the concept proposed by Roy Wagner of culture as invention which, in mãe's fictional world, becomes a key element to understand the feminine as a cultural construction.
\end{abstract}

KEYWORDS: Culture; Portuguese language literature; feminine.

Recebido em: 29/10/2014 Aprovado em: 25/02/2015 